\title{
Sulphasalazine induced seminal abnormalities in ulcerative colitis: results of mesalazine substitution
}

\author{
S A RILEY, J LECARPENTIER, V MANI, M J GOODMAN, B K MANDAL, \\ AND L A TURNBERG
}

From the University Department of Medicine and Department of Immunology, Hope Hospital, Salford, Leigh Infirmary, Bury General Hospital and Monsall Hospital, Manchester

SUMmARY Seminal abnormalities are commonly found during sulphasalazine treatment. Although these changes appear reversible after drug withdrawal this may result in colitis relapse. Animal studies suggest that 5-aminosalicylic acid, the active component of sulphasalazine, does not impair fertility. Sixteen patients with quiescent ulcerative colitis were studied. Each patient produced three samples of semen at weekly intervals. Of the 48 samples analysed $39.6 \%$ showed oligospermia, $41.7 \%$ showed an increased number of abnormal forms and $91.7 \%$ showed impaired motility. Nine patients substituted enteric coated mesalazine (5-aminosalicylic acid) for sulphasalazine for a minimum period of three months. During this time one patient developed a salmonella associated colitis relapse; the others remained well. Improvement in sperm count $(p<0.02)$, motility $(p<0.001)$ and morphology $(p<0.02)$ occurred in all cases. To date, four successful pregnancies have resulted, three in couples complaining of long term infertility. Treatment with enteric-coated mesalazine allows the recovery of seminal abnormalities induced by sulphasalazine in patients with colitis.

Since its introduction in 1942 sulphasalazine (SASP) has proved useful in the management of ulcerative colitis. It is of some benefit in mild and moderately active colitis ${ }^{12}$ but its main value is its ability to reduce disease relapse rate $^{34}$ and lifelong treatment is usually recommended.

Chemically, SASP is an unusual drug having two components: 5-aminosalicylic acid (5ASA) and sulphapyridine, linked by an azo bond. When taken by mouth most of the drug reaches the caecum intact where it is split by bacterial azoreductases into its component parts. 5 Studies in active colitis have shown that 5ASA is the active therapeutic component $^{t-x}$ and suggest that its action is mainly topical. ${ }^{9}$ When taken by mouth, however, 5ASA is rapidly absorbed in the small intestine ${ }^{10}$ and is unlikely to reach the colon in therapeutic concentrations. Azo

Address for correspondence: Dr S A Riley. University Department of Medicine, Hope Hospital, Eccles Old Road, Salford M6 8HD

Received for publication 8 January 1987. linkage to sulphapyridine prevents this absorption and allows delivery of 5ASA to its site of action.

Unfortunately many patients are denied the beneficial effects of SASP as unwanted effects are common. As most of these are attributed to the sulphapyridine component ${ }^{11}$ '2 new drug formulations have been developed to deliver 5ASA to the colon without the need for this potentially toxic carrier. ${ }^{1314}$ The evaluation of such compounds should involve not only an assessment of their clinical efficacy but also ensure their freedom from recognised SASP side effects.

Male infertility is one such side effect that has caused considerable concern in recent years. Although seminal parameters and fertility improve after drug withdrawal this leaves the patient at risk of colitis relapse. The aim of the present study was, therefore, to assess the effect of enteric coated mesalazine (5ASA) substitution of SASP treatment on seminal activity in patients with chronic ulcerative colitis. 


\section{Methods}

PATIENTS

Sixteen patients (aged 23-39 years) with chronic ulcerative colitis in well established clinical remission were studied. Each gave informed consent and the study protocol was approved by Salford Area Health Authority Ethical Committee. All had been taking sulphasalazine (Salazopyrin, Pharmacia) 2-3 g daily in divided doses for a minimum period of three months (mean 2.8 years). Patients with a history of colitis relapse or febrile illness in the three months preceding the study period and patients taking other drugs known to affect fertility were excluded.

Three samples of semen were produced at intervals of at least one week. Samples were obtained by masturbation after a minimum of 72 hours abstinence and were analysed within 60 minutes of emission. After liquefaction, ejaculate volume was noted and sperm density, motility and morphology were determined by standard methods ${ }^{15}$ (normal values: sperm density more than $40 \times 10^{6} / \mathrm{ml}$, sperm morphology less than $30 \%$ abnormal forms and sperm motility more than $60 \%$ actively progressive forms within one hour from emission). During morphological assessment particular note was made of increased numbers of large headed sperm forms (normal range: less than $3 \%)^{16}$

After this initial assessment nine patients substituted enteric coated mesalazine (Asacol, Tillotts Laboratories) for sulphasalazine. Dose equivalence was based on a scale of $1 \mathrm{~g}$ sulphasalazine to $400 \mathrm{mg}$ mesalazine. After a minimum period of three months a further three samples of semen were analysed.

STATISTICAL ANALYSIS

All results are expressed as mean $\pm \mathrm{SD}$. Comparisons of semen volume, sperm mortility and sperm mor- phology during the two treatment periods were analysed using paired $t$ tests. Sperm counts, however, were not normally distributed and were therefore analysed using Wilcoxon's matched-pairs test.

\section{Results}

Of the 48 samples analysed during SASP treatment $39.6 \%$ showed oligospermia, $41.7 \%$ an increased number of abnormal forms and $91.7 \%$ impaired motility (Fig. 1). Only one of the 16 patients had normal values for sperm count, motility and morphology in all three samples. No significant correlation could be found between seminal impairment and SASP dose. Morphological assessment revealed an increased number of large headed 'megalo' forms in 29 of the 48 samples (Fig. 2).

Of the nine patients who substituted mesalazine for SASP eight remained well. One patient developed a relapse of his colitis associated with a salmonella infection but remained on mesalazine throughout and was studied three months after resolution of his symptoms.

Mesalazine substitution was associated with improvement in all seminal parameters. Mean sperm count rose from $50 \pm 66 \cdot 7 \times 10^{\circ} / \mathrm{ml}$ to $118 \pm 122 \times 10^{\circ} / \mathrm{ml}$ $(\mathrm{p}<0 \cdot 02)$, sperm motility rose from $20 \pm 20 \cdot 3 \%$ to $52 \pm 17.1 \% \quad(p<0.001)$ and the percentage of abnormal sperm forms fell from $32 \pm 17.6 \%$ to $16 \pm 8.7 \% \quad(p<0 \cdot 02)$. Semen volume, however, showed no significant change $(p>0 \cdot 2)$. Despite marked within subject variability, which is well recognised in normal fertile men, ${ }^{17}$ individual results show consistent improvement for each patient and also within each individual sample (Fig. 3). Megalo forms, however, found in excess in $67 \%$ of the samples during SASP treatment persisted in $46 \%$ of samples after three months mesalazine treatment.
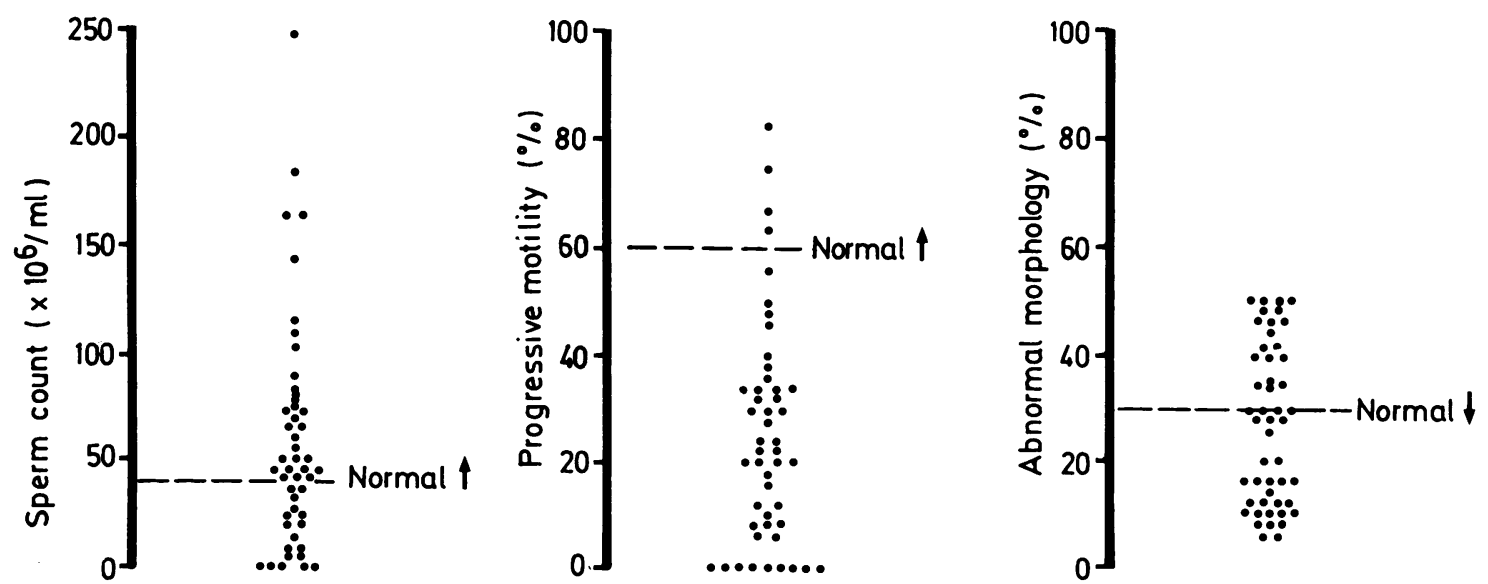

Fig. 1 Seminal activity during sulphasalazine treatment. 


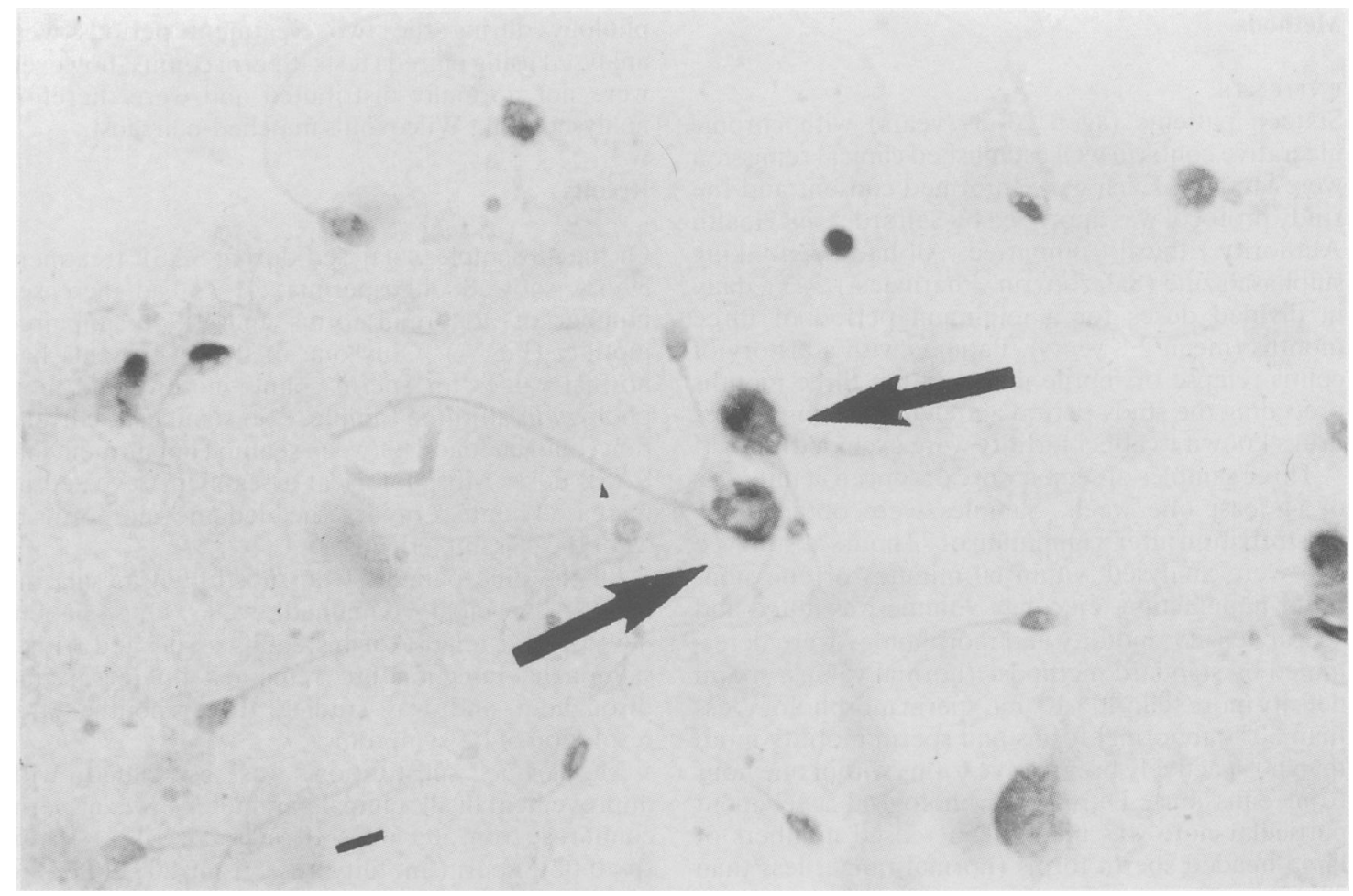

Fig. 2 Large headed 'megalo' sperm forms (arrows), excessive numbers often seen during sulphasalazine treatment.

In contrast with the changes seen in sperm count and morphology, where most values returned to the normal range, sperm motility showed suboptimal improvement. This prompted reassessment of two patients after 12 months of mesalazine treatment and in both further improvement occurred and megalo forms disappeared. Sperm motility, however, remained subnormal in one patient (Fig. 4).

Five pregnancies were conceived by four patients after a mean interval of 3.7 months on mesalazine treatment. Three of these pregnancies occurred in separate couples complaining of longterm infertility and in whom investigation of the wife had proved normal. One pregnancy conceived five weeks after substitution miscarried while the others have resulted in the delivery of four healthy offspring.

\section{Discussion}

Sulphasalazine associated male infertility was first reported independently by Levi et $\boldsymbol{l}^{1 \mathrm{1}}$ and by Toth ${ }^{19}$ in 1979. Both described a small number of men complaining of infertility in whom seminal impairment improved on drug withdrawal and pregnancies ensued. Others have confirmed these findings ${ }^{21122}$ and surveys show that the majority of men taking SASP have some degree of seminal impairment..$^{2.324}$

This impairment is characterised by oligospermia, poor sperm motility and an increased number of abnormal sperm forms either alone or in combination. A characteristic ballooned cell type, the megalo form, has also been described..$^{19}$ In a study assessing sperm head size by image analysis Hudson et al ${ }^{25}$ found that patients taking SASP had significantly larger sperm heads than non-colitic oligospermic men. After drug withdrawal, however, sperm head size increased further before becoming smaller and did not return to normal within the study period. Persistence of megalo forms after short term drug withdrawal has also been noted by others ${ }^{19}$ and in the present study $46 \%$ of samples contained megalo forms after three months mesalazine treatment. After 12 months mesalazine substitution excessive numbers of megalo forms were not present though the number of samples studied was small.

Nuclear chromatin abnormalities have also been observed in the sperm heads of patients with inflammatory bowel disease. Although it has been suggested that these abnormalities are characteristic of 

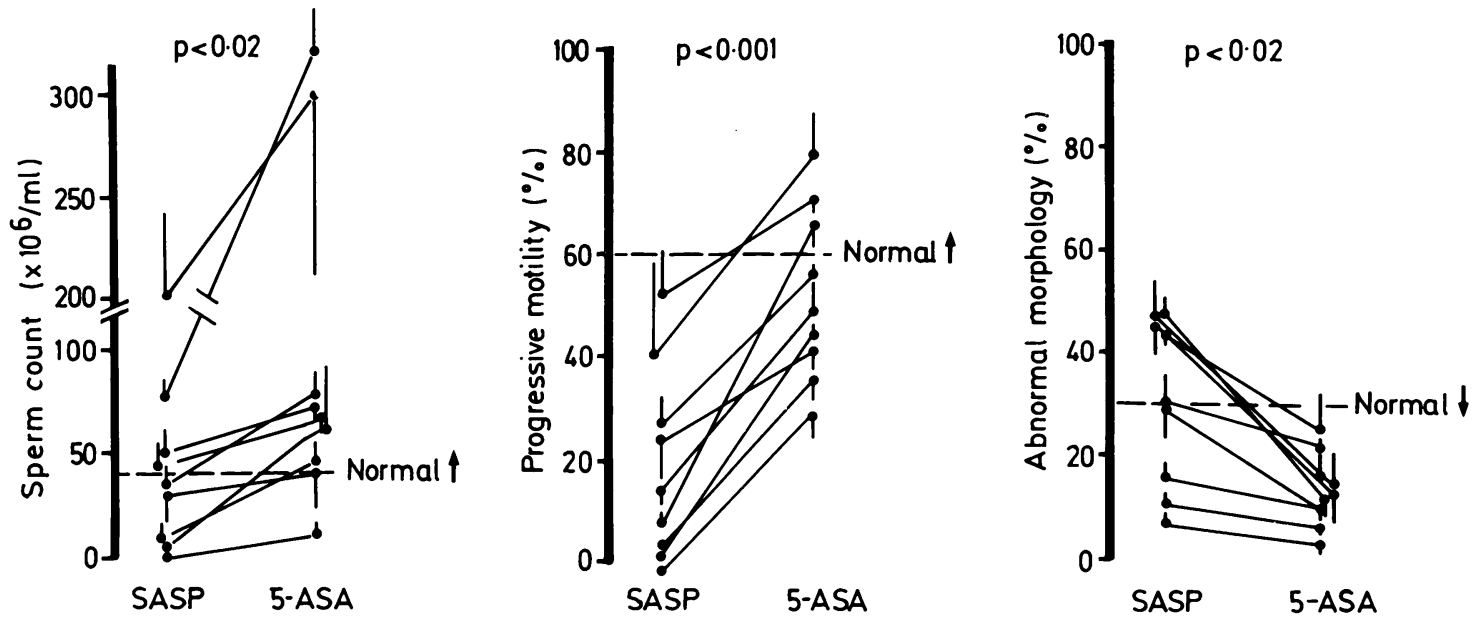

Fig. 3 Influence of mesalazine substitution on seminal activity. Mean $\pm S D$ of three samples during each treatment period $(n=9)$.

inflammatory bowel disease their relationship to SASP treatment has been questioned. ${ }^{2 h}$

In the present study motility was the seminal characteristic most frequently affected by SASP treatment. It was, therefore disappointing to find only partial recovery of motility during mesalazine treatment, especially as other indices improved so dramatically. The published data, however, suggest that this may occur after SASP withdrawal alone ${ }^{27}$ and a mesalazine effect thus seems unlikely.

The mechanisms by which SASP induces seminal abnormalities remains obscure. ${ }^{2 x}$ The prolonged recovery period after drug withdrawal suggests an

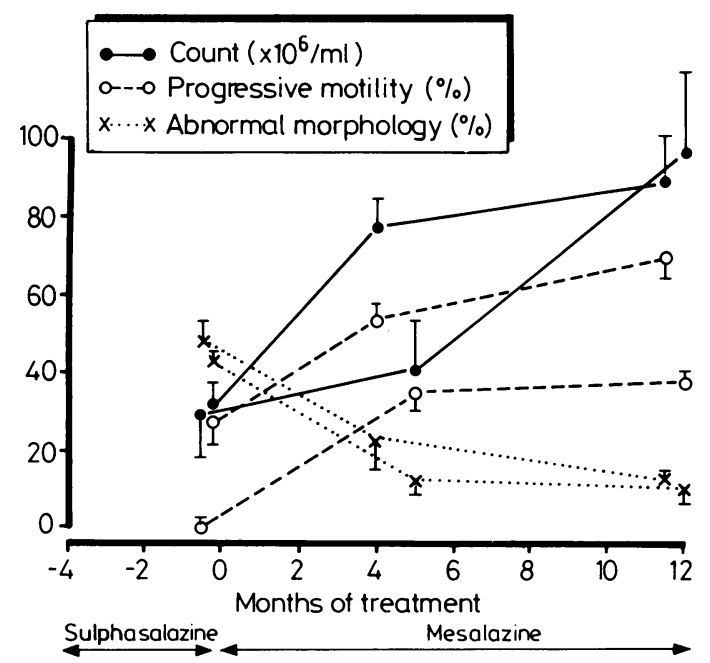

Fig. 4 Results of prolonged mesalazine substitution in two patients. Mean $\pm S D$ of three samples. effect early in spermatogenesis, which in man takes $74 \pm 4$ days,,$^{29}$ and direct drug toxicity at this stage seems likely. Animal studies suggest the sulphapyridine component of SASP is responsible while 5ASA does not appear to affect fertility..x

Studies of human seminal parameters with alternative salicylate formulations have been limited. Three cases of SASP associated infertility successfully treated with Balsalazide have been reported." Chemically, this compound comprises 5ASA linked by an azo bond to an inert, non-absorbed carrier, 4 amino- $\beta$-benzoylalanine. Although pharmacokinetic studies have shown it is metabolised in a similar manner to SASP"1 studies of its clinical efficacy are awaited.

In addition to the present study two cases of SASP infertility treated with enteric coated mesalazine (Asacol) have been reported..$^{33}$ This formulation aims to deliver 5ASA to the colon by means of its coating, Eudragit $S$, an acrylic resin that disintegrates releasing 5ASA only above $\mathrm{pH} \mathrm{7,} \mathrm{the}$ prevailing $\mathrm{pH}$ of the terminal ileum and colon. ${ }^{3.35}$ Clinically, it may be useful for patients intolerant of $\mathrm{SASP}^{36}$ and preliminary studies suggest it may be as effective as SASP in the maintenance treatment of ulcerative colitis. ${ }^{37}$ The present studies show that it allows the recovery of seminal abnormalities commonly seen in patients taking maintenance SASP treatment for chronic ulcerative colitis.

The authors gratefully acknowledge the advice of $\mathrm{Dr}$ M Haeney, Department of Immunology, Hope Hospital, Ms J Rostron for preparation of the manuscript, and the participation of their patients. Preliminary reports of this study were presented at 
the BSG Meeting, September 1986 (Gut 1986; 27: A1272) and at the World Congress of Gastroenterology, September 1986 (Dig Dis Sci 1986; 31S: $3195)$.

\section{References}

1 Lennard-Jones JE, Longmore AJ, Newell AC, Wilson CWE, Avery-Jones F. An assessment of prednisolone, salazopyrin and topical hydrocortisone hemisuccinate used as out-patient treatment for ulcerative colitis. Gut 1960; 1: 217-22.

2 Baron JH, Connell AM, Lennard-Jones JE, AveryJones F. Sulphasalazine and salicylazosulphadimidine in ulcerative colitis. Lancet 1962; i: 1094-6.

3 Misiewicz JJ, Lennard-Jones JE, Connell AM, Baron $\mathrm{JH}$, Avery-Jones F. Controlled trial of sulphasalazine in maintenance therapy for ulcerative colitis. Lancet 1965; i: $185-8$.

4 Dissanayake AS, Truelove SC. A controlled therapeutic trial of long-term maintenance treatment of ulcerative colitis with sulphasalazine (Salazopyrin). Gut 1973; 14: 923-6.

5 Peppercorn MA, Goldman P. The role of intestinal bacteria in the metabolism of salicylazosulphapyridine. J Pharmacol Exp Ther 1972; 181: 555-62.

6 Azad Khan AK, Piris J, Truelove SC. An experiment to determine the active therapeutic moeity of sulphasalazine. Lancet 1977; ii: 892-5.

7 Van Hees PAM, Bakker JH, van Tongeren JHM. Effect of sulphapyridine, 5-aminosalicylic acid and placebo in patients with idiopathic proctitis: a study to determine the active therapeutic moeity of sulphasalazine. Gut 1980; 21: 632-5.

8 Klotz U, Maier K, Fischer C, Heinkel K. Therapeutic efficacy of sulphasalazine and its metabolites in patients with ulcerative colitis and Crohn's disease. $N$ Engl J Med 1980; 303: 1499-502.

9 Campieri M, Lanfranchi GA, Bazzocchi G, et al. Treatment of ulcerative colitis with high-dose 5aminosalicylic acid enemas. Lancet 1981; ii: 270-1.

10 Haagen Nielsen $\mathrm{O}$, Bondesen $\mathrm{S}$. Kinetics of 5aminosalicylic acid after jejunal instillation in man. $\mathrm{Br} J$ Clin Pharmacol 1983; 16: 738-40.

11 Schröder H, Evans DAP. Acetylator phenotype and adverse effects of sulphasalazine in healthy subjects. Gut 1972; 13: 278-84.

12 Das KM, Eastwood MA, McManus JPA, Sircus W. Adverse reactions during salicylazosulphapyridine therapy and the relation with drug metabolism and acetylator phenotype. $N$ Engl J Med 1973; 289: 491-5.

13 Goldman P. Will there be a next generation of sulphasalazine? Gastroenterology 1982; 83: 1138-41.

14 Hawkey CJ. Salicylates for the sulpha-sensitive patient with ulcerative colitis? Gastroenterology 1986; 90: 1083-4

15 Zanereld LJD, Polakoski KL. In: Hafez ESE, ed. Techniques in human andrology. Amsterdam: Elsevier/ North Holland Biomedical Press, 1977.

16 Schwarts D, Mayoux MJ, Guihard-Moscato ML, et al.
Study of sperm morphologic characteristics in a group of 833 fertile men. Andrologia 1984; 16: 423-38.

17 Sherins RJ, Brightwell D, Sternthal PM. Longitudinal analysis of semen in fertile and infertile men. In: Troen $\mathrm{P}$, Nankin HR, eds. The testis in normal and infertile men. New York: Raven Press, 1977: 473-88.

18 Levi AJ, Fisher AM, Hughes L, Hendry WF. Male infertility due to sulphasalazine. Lancet; 1979; ii: 276-8

19 Toth A. Reversible toxic effect of salicylazosulphapyridine on semen quality. Fertil Steril 1979; 31: 538-40.

20 Grieve J. Male infertility due to sulphasalazine. Lancet 1979; ii: 464

21 Traub AI, Thompson W, Carville J. Male infertility due to sulphasalazine. Lancet 1979; ii: 539-40.

22 Collen MJ. Azulfidine-induced oligospermia. Am J Gastroenterol 1980; 74: 441-2.

23 Birnie GG, McLeod TIF, Watkinson G. Incidence of sulphasalazine-induced male infertility. Gut 1981; 22: 452-5.

24 Freeman JG, Reece VAC, Venables CW. Sulphasalazine and spermatogenesis. Digestion 1982; 23: 68-71.

25 Hudson E, Dore C, Sowter C, Toovey S, Levi AJ. Sperm size in patients with inflammatory bowel disease on sulphasalazine therapy. Fertil Steril 1982; 37: 77-84.

26 Hrudka F, Singh A. Sperm nucleomalacia in men with inflammatory bowel disease. Arch Androl 1984; 13: 37-57.

27 Toovey S, Hudson E, Hendry WF, Levi AJ. Sulphasalazine and male infertility: reversibility and possible mechanism. Gut 1981; 22: 445-51.

28 O'Morain C, Smethurst P, Dore CJ, Levi AJ. Reversible male infertility due to sulphasalazine: studies in man and rat. Gut 1984; 25 : $1078-84$.

29 Heller CG, Clermant Y. Kinetics of the germinal epithelium in man. Rec Prog Horm Res 1964; 20: 545.

30 McIntyre PB, Lennard-Jones JE. Reversal with balsalazide of infertility caused by sulphasalazine. $\mathrm{Br}$ Med J 1984; 288: 1652-3.

31 Chan RR, Pope DJ, Gilbert AP, Sacra PJ, Baron JH, Lennard-Jones JE. Studies of two novel sulphasalazine analogs. Dig Dis Sci 1983; 28: 609-15.

32 Cann PA, Holdsworth CD. Reversal of male infertility on changing treatment from sulphasalazine to 5aminosalicylic acid. Lancet 1984; i: 1119.

33 Shaffer JL, Kershaw A, Berrisford MH. Sulphasalazineinduced infertility reversed on transfer to 5aminosalicylic acid. Lancet 1984; i: 1240.

34 Dew MJ, Hughes PJ, Lee MG, Evans BK, Rhodes J. An oral preparation to release drugs in the human colon. $\mathrm{Br}$ J Clin Pharmacol 1982; 14: 405-8.

35 Dew MJ, Ryder REJ, Evans N, Evans BK, Rhodes J. Colonic release of 5-aminosalicylic acid from an oral preparation in active ulcerative colitis. $\mathrm{Br} J$ Clin Pharmacol 1983; 16: 185-7.

36 Dew MJ, Harries AD, Williams G, Evans BK, Rhodes J. Treatment of ulcerative colitis with oral 5aminosalicylic acid in patients unable to take sulphasalazine. Lancet 1983 ; ii: 801 .

37 Dew MJ, Hughes P, Harries AD, Williams G, Evans $\mathrm{BK}$, Rhodes $\mathrm{J}$. Maintenance of remission in ulcerative colitis with an oral preparation of 5-aminosalicylic acid. Br Med J 1982; 285: 1012 . 